\title{
Studies on Development of Controlled Release Matrix Tablets of Camptothecin-An Anticancer Drug
}

\author{
Buchi Naidu Nalluri, Pavan Kumar Devineni, Maheswari Karna Male, Ashraf Sultana Shaik and \\ Chandra Teja Uppuluri
}

Department of Pharmaceutics, KVSR Siddhartha College of Pharmaceutical Sciences, Vijayawada-520010, AP, INDIA.

\begin{abstract}
Objectives: The present investigation was carried out with an objective of formulating prototype controlled release (CR) matrix tablets of Camptothecin (CPT), an anti-cancer drug. Experimental: pH solubility profile studies of CPT and solubility of CPT in different surfactants were carried out. Controlled release tablets were prepared by direct compression method using hydroxyl propylmethyl cellulose (HPMC LVCR and HPMC K4M) as release retardants. The effect of different grades of microcrystalline cellulose (MCC) like Avicel PH 101 and Avicel PH 105 and solubilizing agents like cyclodextrins were included in the formulations and their effect on CPT release from tablets were studied. Results and Discussion: Solubility studies were conducted in order to select suitable dissolution medium for CPT. Based on the solubility studies, $0.1 \mathrm{~N} \mathrm{HCl}$ with $3 \% \mathrm{w} / \mathrm{v} \mathrm{SLS}(\mathrm{pH} 1.2)$ was selected as dissolution medium. The FTIR and DSC results indicated that there was no in situ interaction between CPT and the selected excipients in the formualtions. Formulations containing $20 \% \mathrm{w} / \mathrm{w}$ of hydroxypropyl- $\beta$-cyclodextrin with Avicel $\mathrm{PH} 105$ as filler and HPMC k4M as release retardant gave superior CPT release of $98.40 \pm 1.02 \%$ at the end of 12 $\mathrm{h}$ and fulfilled the regulatory requirements. The Higuchi square root model showed higher correlation coefficient values (0.949-0.990) indicating diffusion was the release mechanism for CPT from tablets. Conclusion: CPT can be formulated in to CR matrix tablets using HPMC K4M as release retardant and MCC as filler for better therapeutic efficacy.
\end{abstract}

Key words: Camptothecin, CR matrix tablets, Cyclodextrins, Dissolution studies, Solubility studies.

\section{INTRODUCTION}

Camptothecin (CPT) is a poorly water-soluble anti-cancer drug and used for the treatment of colorectal, breast, lung and ovarian cancers and according to the BCS system (Class-IV) its dissolution is the rate-limiting step for absorption. ${ }^{1,2}$ As a result, the use of CPT is limited by its solubility issue in several clinical trials and research was carried out on development of water soluble analogues of CPT. The elimination half life of CPT is 58.7 mins. $^{3}$ The dose of the CPT is $200 \mathrm{mg}$ /day for individual weighing $70 \mathrm{~kg} .{ }^{4}$ Since the elimination half life is short and its solubility is quite low, enhanced dissolution and sustained/controlled release characteristics are needed for CPT for better therapeutic efficacy.
To overcome hurdles like poor solubility and hydrolytic processes of CPT, development of adequate drug carriers is gaining increasing attention. Different approaches have been utilized to alleviate solubility and stability issues of CPT. ${ }^{3-5}$ Most of the research works were focused on the particulate delivery of the CPT and its analogues especially as liposomes and nanoparticles. ${ }^{6-11}$ Very few reports were published on the delivery of CPT and its analogues by oral matrix tablet technology. ${ }^{12,13}$

In the present study, we aim at developing prototype CR matrix tablets of CPT keeping in view of its shorter elimination half life. To achieve the sink conditions for effective dissolution of CPT, studies on the selection of appropriate dissolution medium were also
Submission Date : 18-12-2014 Revision Date : :05-02-2015 Accepted Date : :02-04-2015

DOI: 10.5530/ijper.49.4.6 Correspondence Address Dr. Buchi Naidu Nalluri KVSRSiddhartha College of Pharmaceutical Sciences, Vijayawada-520010, AP, INDIA.

EMail:buchinalluri@yahoo. com

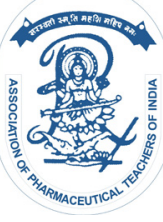

www.ijper.org 


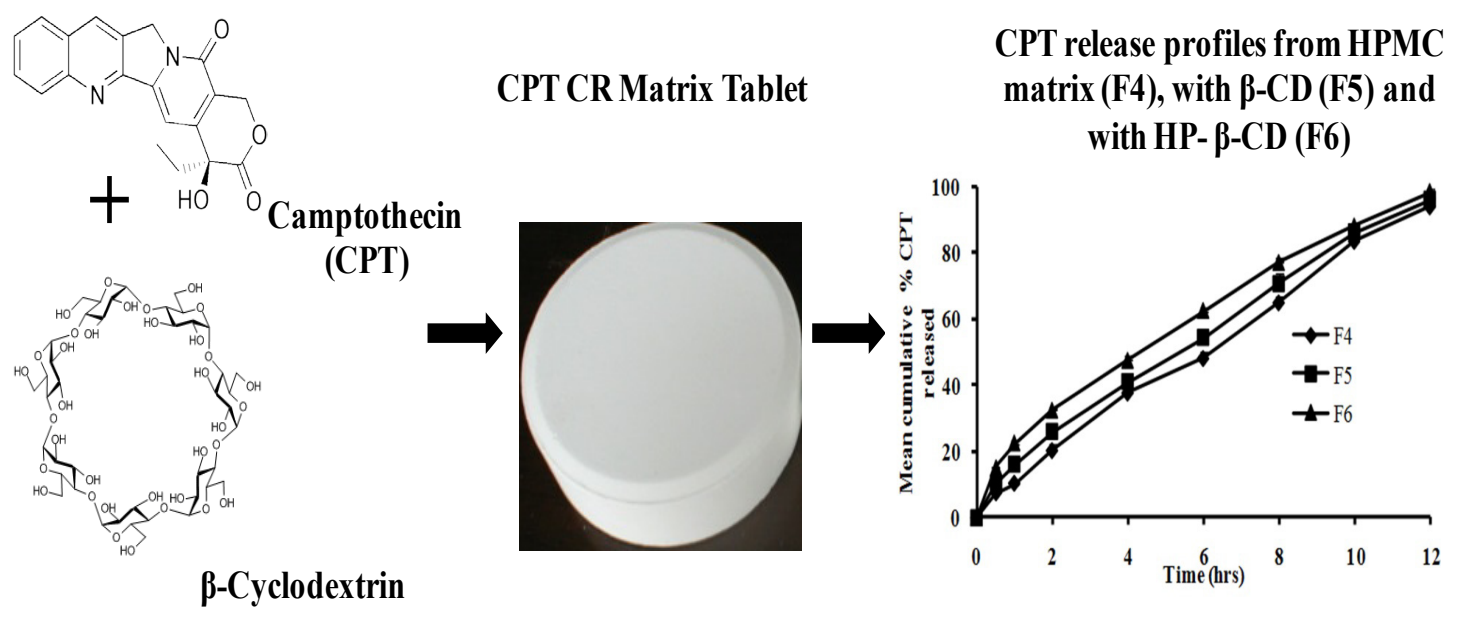
CPT release profiles from HPMC matrix (F4), with $\beta$-CD (F5) and with HP- $\beta-C D$ (F6)

Graphical Abstract

carried out based on the solubility studies. CR matrix tablets of CPT were prepared using HPMC (LVCR100 and $\mathrm{K} 4 \mathrm{M}$ ) as release retardants and MCC (Avicel PH101 and Avicel PH105) as filler. Since, CPT is poorly watersoluble drug, its release from the CR matrix tablets is incomplete and therapeutically effective drug levels may not be achieved. Literature survey revealed that the solubility and stability of CPT was successfully enhanced by inclusion complexation with cyclodextrins. ${ }^{3-5}$ Hence, in this investigation solubilizing excipients like cyclodextrins ( $\beta$-cyclodextrin and hydroxyl propyl- $\beta$-cyclodextrin) were included in the formulations and their effect on the CPT release was studied in order to achieve therapeutically effective levels of CPT CR from matrix tablets.

\section{MATERIALS AND METHODS}

\section{Reagents and Chemicals}

Camptothecin was obtained from Gamma Technology Development Co. Ltd. (Shenzhen, China). HPMC (LVCR100 and K4M grades) and MCC (Avicel PH101 and Avicel PH105 grades) were obtained from Colorcon Asia Pvt.Ltd. Goa and FMC Biopolymers, USA, respectively. $\beta$-cyclodextrin and hydroxyl propyl- $\beta$ cyclodextrin were obtained from Roquette Pharma, France. Tween 20 and Sodium lauryl sulphate were purchased from Lobachemie, Mumbai and Merck Pvt. Ltd., Mumbai respectively. Magnesium stearate and talc were purchased from SD fine chemicals Ltd., Mumbai. All

\begin{tabular}{|c|c|c|c|c|c|c|}
\hline $\begin{array}{l}\text { Ingredients } \\
\text { (mg/tab) }\end{array}$ & F1 & F2 & F3 & F4 & F5 & F6 \\
\hline СРТ & 50 & 50 & 50 & 50 & 50 & 50 \\
\hline $\begin{array}{c}\text { HPMC } \\
\text { (LVCR100) }\end{array}$ & - & 22.5 & 22.5 & - & - & - \\
\hline HPMC (K4M) & 22.5 & - & - & 30 & 30 & 30 \\
\hline$\beta-C D$ & - & - & - & - & 30 & - \\
\hline HP- $\beta-C D$ & - & - & - & - & - & 30 \\
\hline $\begin{array}{c}\text { MCC (AVICEL } \\
\text { PH101) }\end{array}$ & - & - & 76 & - & - & - \\
\hline $\begin{array}{c}\text { MCC (AVICEL } \\
\text { PH105) }\end{array}$ & 76 & 76 & - & 68.5 & 38.5 & 38.5 \\
\hline $\begin{array}{c}\text { Magnesium } \\
\text { Stearate }\end{array}$ & 0.75 & 0.75 & 0.75 & 0.75 & 0.75 & 0.75 \\
\hline Talc & 0.75 & 0.75 & 0.75 & 0.75 & 0.75 & 0.75 \\
\hline $\begin{array}{l}\text { Total weight } \\
\text { (mg/tab) }\end{array}$ & 150 & 150 & 150 & 150 & 150 & 150 \\
\hline
\end{tabular}



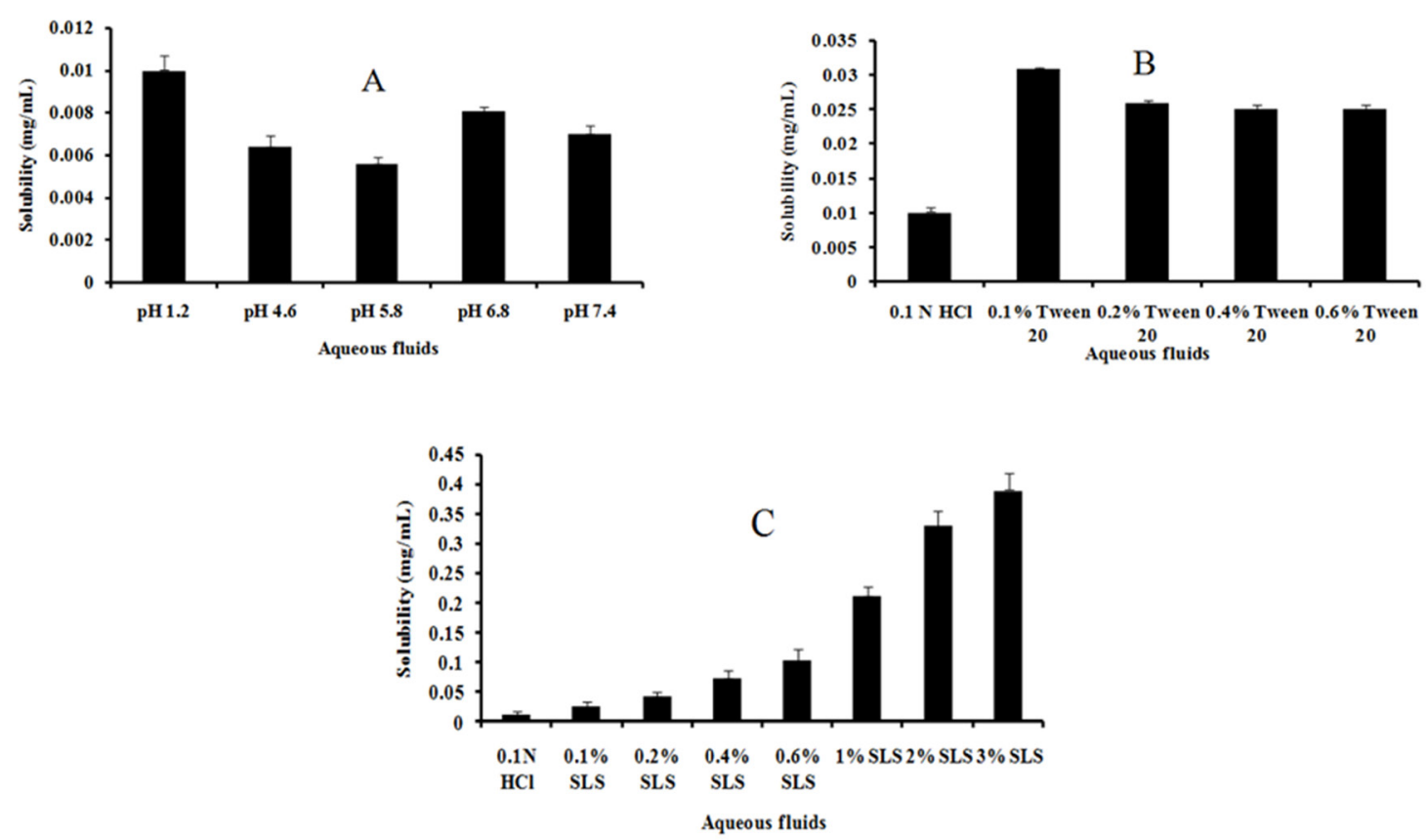

Figure 1: (A) pH- solubility profile of CPT; (B) Solubility profile of CPT in $0.1 \mathrm{~N} \mathrm{HCl}$ with different percentages of Tween20; (C) Solubility profile of CPT in $0.1 \mathrm{~N} \mathrm{HCl}$ with different percentages of SLS

other reagents were of analytical grade, and double distilled water was used throughout. All solvents used in HPLC analysis were of HPLC grade and filtered using a $0.45 \mu \mathrm{m}$ nylon filter.

\section{Analytical Method}

Quantitative analysis of CPT was performed on a HPLC system (Shimadzu HPLC, class VP series) with two LC-20 AD pumps, SIL-20 A auto sampler, PDA detector SPD-M20A VP, and Inertsil $\mathrm{C}_{18}$ column $(250 \times 4.6$ $\mathrm{mm}$ dimensions and $5 \mu \mathrm{m}$ particle size). The HPLC system was equipped with "LC-Solution" software to acquire and process the data. Mobile phase consisting of $15 \mathrm{mM}$ ammonium acetate ( $\mathrm{pH}$ 6.5): acetonitrile (60:40) was used in isocratic mode and the mobile phase was filtered through nylon disc filter of $0.45 \mu \mathrm{m}$ (Millipore) and sonicated for $3 \mathrm{~min}$ before use. The flow rate was $1 \mathrm{ml} / \mathrm{min}$ and the injection volume was $20 \mu \mathrm{l}$. PDA detection was performed at $254 \mathrm{~nm}$ and the separation was achieved at ambient temperature. Under these conditions the CPT was eluted at $6.8 \mathrm{~min}$ without any interference peaks.

\section{Solubility Studies}

Excess amounts of CPT $(10 \mathrm{mg})$ was added to 15 $\mathrm{ml}$ of each fluid in a $25 \mathrm{ml}$ stopper conical flask and the mixtures were shaken for 48 hours at room temperature $\left(37 \pm 1^{\circ} \mathrm{C}\right)$ on orbital rotary shaker incubator
(Remi, India). During 48 hours of shaking $1 \mathrm{ml}$ aliquots were withdrawn at different time intervals and filtered immediately using a $0.45 \mu$ nylon disc filter. The filtered samples were diluted suitably and assayed for CPT by above HPLC method. Shaking was continued until three consecutive estimations were same. The solubility experiments were run in triplicate.

\section{Characterization of CPT Tablet Powder Blends}

\section{Fourier Transmittance Infrared Spectroscopic (FT-IR) Studies}

The FT-IR spectra of pure CPT and CPT with selected excipients like HPMC LVCR 100, HPMC K4M, Avicel PH 101, Avicel PH 105, $\beta-C D$, HP- $\beta$-CD, Magnesium stearate and Talc was measured using ATR-FTIR spectrophotometer (Bruker, Germany). ATR spectra were measured over the wave number range of 4000$500 \mathrm{~cm}^{-1}$ at a resolution of $1.0 \mathrm{~cm}^{-1}$. The powder sample is simply placed onto the ATR crystal and the sample spectrum is collected.

\section{Differential Scanning Calorimetry (DSC) studies}

Thermal analysis of pure CPT and CPT with selected excipients like HPMC LVCR 100, HPMC K4M, Avicel PH 101, Avicel PH 105, $\beta$-CD, HP- $\beta$-CD, Magnesium stearate and Talc was performed using DSC (Mettler Star SW 8.10). The sample was sealed in a crimped 


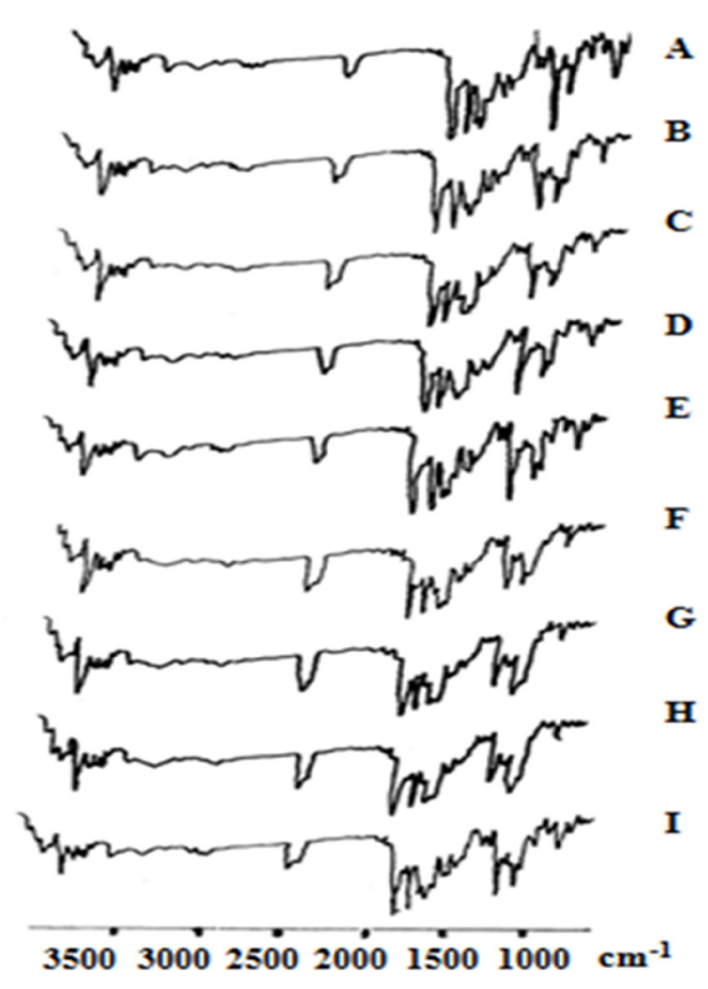

Figure 2: FTIR Spectra of CPT - (A) CPT; (B) CPT-HPMC LVCR100; (C) CPT-HPMC K4M; (D) CPT- $\beta$-CD; (E) CPT-HP$\beta$-CD; (F) CPT-Avicel PH101; (G) CPT-AvicelPH105;(H) CPTMagnesium Stearate; (I) CPT-Talc

aluminium pan by application of the minimum possible pressure and heated at a rate of $10^{\circ} \mathrm{C} / \mathrm{min}$ from $25-400^{\circ} \mathrm{C}$ in a nitrogen atmosphere. An empty aluminium pan was utilized as the reference pan.

\section{Preparation of CPT CR Matrix Tablets}

CPT CR matrix tablets were prepared by direct compression method, as per formulae given in Table 1. HPMC K4M and HPMC LVCR 100 were used as release retarding materials. Sufficient quantity of MCC (Avicel PH 101 and PH 105) was used to raise the bulk volume of the tablets to a weight of $150 \mathrm{mg}$ each. Talc and magnesium stearate at $0.5 \% \mathrm{w} / \mathrm{w}$ levels were used as glidants/lubricants.

All the ingredients were passed through sieve \# 80 before mixing. Initially drug and polymers were mixed thoroughly and then required quantities of fillers were added and finally the blend was mixed with talc and mixed thoroughly for $5 \mathrm{~min}$ in a poly bag and then required amount of magnesium stearate was added and mixed for another $5 \mathrm{~min}$. Powder blends (for 50 tablets each) of all the above formulations were compressed on single punch tablet press (Cadmach, India) using $8 \mathrm{~mm}$ punches (round shape) at a hardness of $4-4.5 \mathrm{~kg} / \mathrm{cm}^{2}$.

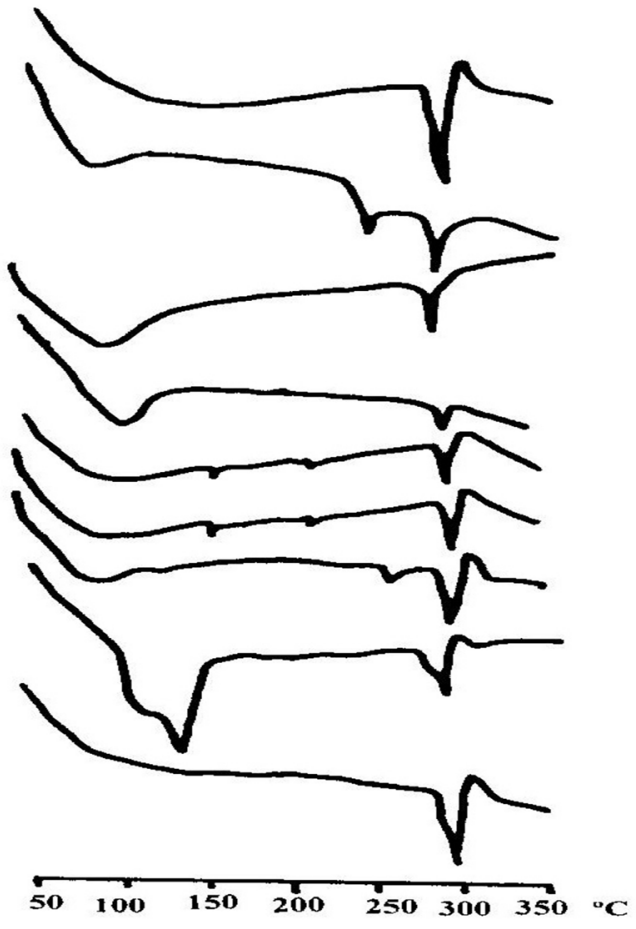

Figure 3: DSC thermograms of CPT - (A) CPT; (B) CPT-HPMC LVCR100; (C) CPT-HPMC K4M; (D) CPT- $\beta$-CD; (E) CPT-HP$\beta$-CD; (F) CPT-Avicel PH101; (G) CPT-AvicelPH105;(H) CPTMagnesium Stearate; (I) CPT-Talc

\section{Evaluation of Flow Properties of powder blend}

The powder blends were evaluated for parameters like bulk density, tapped density, Carr's index, Angle of repose, and Hausner's ratio. ${ }^{14}$

\section{Evaluation of Post-Compression Parameters of CPT CR Matrix Tablets}

The compressed CPT CR matrix tablets were evaluated for properties like drug content, uniformity of weight, friability, hardness and in vitro drug release studies. ${ }^{15}$

\section{In vitro Drug Release Studies}

In vitro drug release studies of CPT CR matrix tablet formulations prepared were carried in $900 \mathrm{ml}$ of $0.1 \mathrm{~N}$ $\mathrm{HCl}$ with $3 \% \mathrm{w} / \mathrm{v}$ SLS as dissolution medium using USP XXI type II (Paddle method) Dissolution Rate Test Apparatus (LABINDIA, DS 8000, Mumbai, India) at 50/75/100 rpm. The temperature was maintained constant at $37 \pm 0.5^{\circ} \mathrm{C} .5 \mathrm{ml}$ aliquots were withdrawn at different time intervals and filtered using a $0.45 \mu$ nylon disc filter and replaced with $5 \mathrm{ml}$ of fresh dissolution medium. The filtered samples were diluted suitably and $10 \mu \mathrm{l}$ conc. $\mathrm{HCl}$ was added and assayed for CPT by HPLC method. The dissolution experiments were conducted in triplicate. 


\section{Release Kinetics and Mechanisms}

Different kinetic models i.e., Zero-order, First-order, Higuchi and release mechanism like Korsmeyer Peppas were applied to interpret the release profile of CPT from matrix systems. ${ }^{16-19}$

\section{RESULTS AND DISCUSSION}

\section{Solubility Studies}

Solubility of CPT in $0.1 \mathrm{~N} \mathrm{HCl}$ was $0.01 \mathrm{mg} / \mathrm{ml}$ and found to be decreased with increase in $\mathrm{pH}$ of the aqueous fluids as CPT it is weakly basic drug (Figure 1A). The solubility of CPT in aqueous fluids of $\mathrm{pH}$ 4.6-7.4 was almost same.

Since CPT is not official in any pharmacopoeia and no official dissolution medium was reported for CPT. Ideally, a dissolution medium should be able to provide sink conditions for the drug (i.e. at least 3 times the highest dose administered should be soluble in medium) and should have a be able to discriminate power i.e able to differentiate different degrees of product performance in terms of cumulative percent of drug released/dissolved. Hence in this investigation an attempt was made to develop a suitable dissolution medium for evaluation the $\mathrm{CR}$ matrix tablets of $\mathrm{CPT}$ with good discriminatory power based on the solubility studies. Hence, $0.1 \mathrm{~N} \mathrm{HCl}$ of $\mathrm{pH} 1.2$ was selected for further development of dissolution medium as it afforded good solubility conditions and also keeping in view the fact that CPT exists in active lactone form in
$\mathrm{pH} 1.2$ fluids. To enhance the sink conditions for CPT in $0.1 \mathrm{~N} \mathrm{HCl}$, solubility studies were further carried out with surfactants like Tween 20 and SLS.

Solubility studies of CPT in $0.1 \mathrm{~N} \mathrm{HCl}$ with different percentages of Tween 20 showed 2-3 fold increase in solubility and but sink conditions can't be maintained (Figure 1B). Solubility studies of CPT revealed that perfect sink conditions were achieved with 0.1 NHCL with $3 \%$ SLS as dissolution medium (Figure 1B). A 39 fold increase in solubility of CPT with $0.1 \mathrm{~N} \mathrm{HCl}(\mathrm{pH} 1.2)$ containing $3 \%$ w/v SLS was achieved, which equals to about 7 times the dose of the CPT in the $900 \mathrm{ml}$ of the dissolution medium (Figure 1C). Moreover, this medium also showed good discrimination between various formulae in terms of cumulative percent of drug released. Hence, $0.1 \mathrm{~N} \mathrm{HCl}$ $(\mathrm{pH} 1.2)$ with $3 \% \mathrm{w} / \mathrm{v}$ SLS was chosen as dissolution medium to develop CR matrix tablets of CPT.

\section{Characterization of CPT Tablet Powder Blends}

\section{FTIR Studies}

FTIR spectrum of CPT showed -OH stretching at $3,426.25 \mathrm{~cm}, \mathrm{C}-\mathrm{C}(=\mathrm{O})-\mathrm{O}$ streching for cyclic ester (lactone) at $1,740.15 \mathrm{~cm}^{-1}, \mathrm{C}=\mathrm{C}$ and $\mathrm{C}-\mathrm{C}(=\mathrm{O})-\mathrm{O}$ stretching for the pyridone at $1649.92 \mathrm{~cm}^{-1}$ and $1,151.42 \mathrm{~cm}^{-1}$, $\mathrm{C}=\mathrm{C}$ and $\mathrm{C}-\mathrm{N}$ stretching for quinoline ring at 1,600.29, $1,572.28$ and $1,437.40 \mathrm{~cm}^{-1}$. Peak at $771.33 \mathrm{~cm}^{-1}$ appears to be a contribution of four adjacent hydrogen bonds on hetero-atomic nucleus. The characteristic absorption bands of CPT were all retained in the FTIR spectra of 1:1 w/w physical mixtures of the CPT and selected
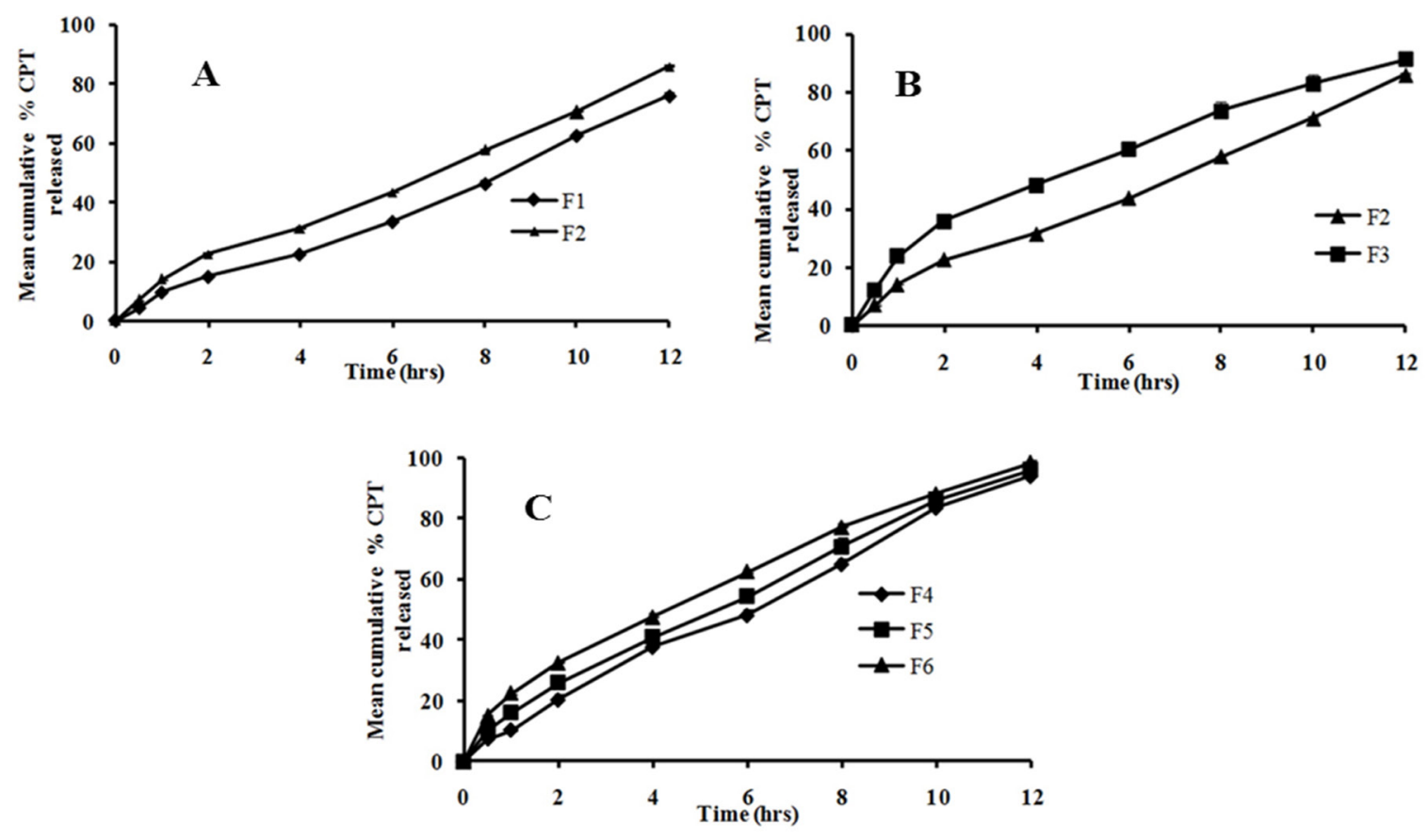

Figure 4: Comparative in vitro release profiles of CPT -(A) using HPMC K4M (F1) and HPMC LVCR100 (F2); (B) using AVICEL PH101(F2) and AVICEL PH101 (F3); (C) without and with cyclodextrins - F4, F5 ( $\beta-C D)$ and F6 (HP- $\beta-C D)$ 


\begin{tabular}{|c|c|}
$\begin{array}{c}\text { Table 2: MDT values for different formu- } \\
\text { lations }\end{array}$ \\
\hline Formulation & MDT (h) \\
\hline F1 (50 RPM) & 4.79 \\
\hline F2 & 3.52 \\
\hline F3 & 2.55 \\
\hline F1 (100 RPM) & 3.16 \\
\hline F4 & 4.87 \\
\hline F5 & 3.39 \\
\hline F6 & 2.54 \\
\hline
\end{tabular}

excipients. These results indicated that there was no in situ interaction between CPT and the selected excipients in the formualtions (Figure 2).

\section{DSC Studies}

DSC thermograms of the pure CPT and CPT with the selected excipients are shown in Figure 3. The CPT showed a sharp endothermic peak at around $290^{\circ} \mathrm{C}$ corresponding to its melting point. ${ }^{20}$ The sharp endothermic melting peak of CPT at $290^{\circ} \mathrm{C}$ was retained in all the thermograms of $1: 1 \mathrm{w} / \mathrm{w}$ physical mixtures of the CPT and selected excipients. These results indicated that the CPT was compatible with all the selected excipients in the formulations.

\section{Evaluation of Flow Properties of Powder Blend}

The powder blends of the formulations were evaluated for the flow properties. The results were in good agreement with specified values. These results indicated that the powder blends of all formulations were suitable to compress tablets by direct compression method. However, flow properties of formulation blends containing Avicel PH 105 were superior when compared to Avicel PH 101.

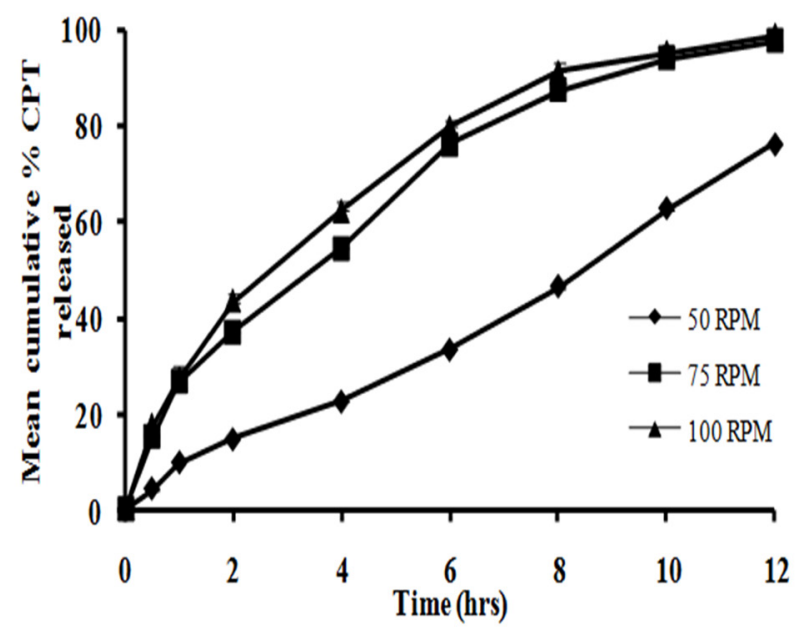

Figure 5: Comparative in vitro release profiles of CPT (F1) with different agitation speeds
Evaluation of Post-Compression Parameters of CPT CR Matrix Tablets

The compressed CPT CR matrix tablets were evaluated for properties like drug content, uniformity of weight, friability and hardness. The drug content of CPT CR matrix tablets was within $100 \pm 1 \%$ of labeled claim. A good degree of uniformity in weight of tablets was achieved for all batches of tablet formulations prepared. The $\%$ deviation was within 3 , which indicates excellent uniformity in weight of all batches of tablet formulations. The friability values of all batches of tablet formulations prepared were less than $1 \%$. The hardness of all batches of tablet formulations compressed ranged between $4-4.5 \mathrm{~kg} / \mathrm{cm}^{2}$.

\section{In vitro Drug Release Studies}

The CPT CR matrix tablets prepared by direct compression using HPMC (LVCR 100 and K4M) as release retardant and MCC (Avicel PH101 and Avicel PH105) as filler were evaluated in paddle type apparatus using $900 \mathrm{ml}$ of $0.1 \mathrm{~N} \mathrm{HCl}$ containing $3 \% \mathrm{w} / \mathrm{v}$ SLS as medium with agitation speed of 50/75/100 rpm.

In the present study, initially the effect of different release retardant polymers on CPT release from CR matrix tablets was studied. F1 and F2 containing K4M and LVCR100 at a level of $15 \% \mathrm{w} / \mathrm{w}$ of total tablet weight with AVICEL PH105 as filler gave 76.13 \pm 1.11 and $86.07 \pm 0.62$ percent CPT releases respectively at end of $12 \mathrm{~h}$. Comparative in vitro dissolution profiles of $\mathrm{F} 1$ and F2 were shown in Figure 4A. The tablets in case of $\mathrm{F} 2$ eroded completely by the end of $8 \mathrm{~h}$, whereas in case of F1, tablets remained intact for $10 \mathrm{~h}$. Being a low viscosity grade (80-120 cp) HPMC polymer when compared to HPMC K4M (3000-5600 cps), the LVCR100 induced faster swelling of the tablet, leading to faster

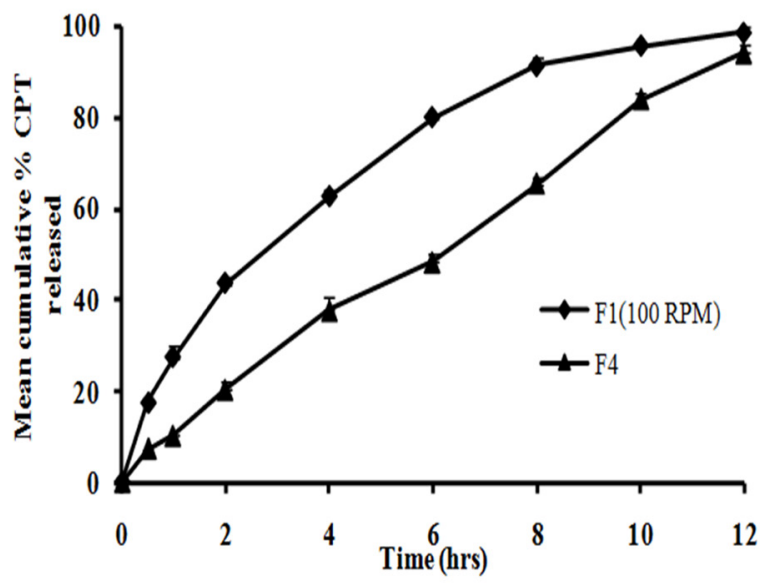

Figure 6: Comparative in vitro CPT release profiles using different concentrations of HPMC K4M - 15\%w/w (F1) and $20 \% w / w(F 4)$ 


\begin{tabular}{|c|c|c|c|c|c|c|c|c|c|}
\hline \multirow{2}{*}{ Formulation } & \multirow{2}{*}{$\begin{array}{c}\text { Mean } \% \\
\text { release (12 } \\
\text { h) }\end{array}$} & \multicolumn{2}{|c|}{ Zero order } & \multicolumn{2}{|c|}{ First order } & \multicolumn{2}{|c|}{ Higuchi } & \multicolumn{2}{|c|}{ Peppas } \\
\hline & & $k_{0}\left(h^{-1}\right)$ & $\mathbf{R}^{2}$ & $k\left(h^{-1}\right)$ & $\mathbf{R}^{2}$ & $\mathrm{~K}_{\mathrm{h}}\left(\mathrm{h}^{-1 / 2}\right)$ & $\mathbf{R}^{2}$ & n & $\mathbf{R}^{2}$ \\
\hline F1 (50 RPM) & $76.14 \pm 1.11$ & 6.06 & 0.991 & 0.10 & 0.934 & 21.54 & 0.912 & 0.734 & 0.980 \\
\hline $\mathrm{F} 2$ & $86.08 \pm 0.62$ & 6.73 & 0.992 & 0.14 & 0.926 & 24.41 & 0.951 & 0.650 & 0.989 \\
\hline F3 & $91.16 \pm 2.49$ & 7.10 & 0.950 & 0.18 & 0.976 & 26.92 & 0.995 & 0.504 & 0.996 \\
\hline F1 (75 RPM) & $97.58 \pm 1.24$ & 7.954 & 0.927 & 0.29 & 0.978 & 30.45 & 0.989 & 0.514 & 0.996 \\
\hline $\begin{array}{l}\text { F1 (100 } \\
\text { RPM) }\end{array}$ & $98.62 \pm 0.94$ & 7.906 & 0.897 & 0.33 & 0.978 & 30.73 & 0.988 & 0.664 & 1.0 \\
\hline $\mathrm{F} 4$ & $94.16 \pm 1.45$ & 7.813 & 0.995 & 0.20 & 0.901 & 28.26 & 0.949 & 0.874 & 0.992 \\
\hline F5 & $96.23 \pm 1.27$ & 7.81 & 0.990 & 0.23 & 0.896 & 28.66 & 0.970 & 0.688 & 0.999 \\
\hline F6 & $98.40 \pm 1.02$ & 7.71 & 0.971 & 0.27 & 0.862 & 28.86 & 0.990 & 0.548 & 0.999 \\
\hline
\end{tabular}

disruption and erosion of CR matrix tablets. The calculated MDT for F1 is $4.79 \mathrm{~h}$, whereas it is $3.52 \mathrm{~h}$ for F2. Based on the MDT values (Table 2), it can be further confirmed that HPMC K4M showed slow swelling rate followed by slower erosion/disintegration of tablet compared with formulations containing HPMC LVCR100 and hence more retarding capacity. Hence, keeping in view of drug release profiles obtained with F1 and F2, HPMC K4M was selected as release retarding polymer.

Later the effect of AVICEL PH101 as a filler on CPT release from CR matrix tablets was studied. F3 containing LVCR100 at a level of $15 \% \mathrm{w} / \mathrm{w}$ of total tablet weight were developed $91.15 \pm 2.49$ percent of CPT at the end of $12 \mathrm{~h}$. Comparative in vitro dissolution profiles of F2 and F3 were shown in Figure 4B. Initial burst release at $1 \mathrm{~h}$ was $14.02 \pm 0.07$ and $23.73 \pm$ $2.32 \%$ respectively for F2 and F3.The tablets in case of F3 were completely eroded by the end of $7 \mathrm{~h}$, whereas in case of F2, tablets eroded by the end of $8 \mathrm{~h}$. Superior burst release was achieved with formulations containing AVICEL PH101 as filler rather than formulations containing AVICEL PH105 as filler, this could be due to quicker swelling of tablets containing AVICEL PH101 compared to formulations containing AVICEL PH105.

Therefore, based on dissolution data obtained with F2 and F3 and keeping in view of the results obtained from pre-compression studies and integrity of the tablets during dissolution, AVICEL PH105 was selected as filler.

As CPT is poorly water soluble drug, the effect of agitation speed on drug release pattern from CR matrix tablets was studied. F1 containing $15 \% \mathrm{w} / \mathrm{w}$ HPMC $\mathrm{K} 4 \mathrm{M}$ of total tablet weight as release retarding polymer and AVICEL PH105 as filler was evaluated under 3 different agitation speeds. Comparative in vitro dissolution, 50,75 and $100 \mathrm{rpm}$ was $76.13 \pm 1.11,97.58 \pm 1.24$ and $98.62 \pm 0.949$ respectively. These results showed clear discrimination that percent drug release increased with increase in agitation speed (Figure 5). Hence, keeping in view of CPT release profiles obtained with different agitation speeds and to maintain hydrodynamics and sink conditions, $100 \mathrm{rpm}$ was selected as agitation speed.

Later effect of release retardant percentage on CPT release from CPT CR matrix tablets was studied. The cumulative percent CPT released at the end of $12 \mathrm{~h}$ from F4 CPT CR matrix tablets containing 20\% w/w of HPMC K4M was 94.16 \pm 1.45 . Whereas, F1 containing $15 \% \mathrm{w} / \mathrm{w}$ HPMC K4M at $100 \mathrm{rpm}$ gave $98.62 \pm 0$ .94 percent CPT release at end of $12 \mathrm{~h}$, which is significantly higher. Comparative in vitro dissolution profiles of $\mathrm{F} 1$ and F4 were shown in Figure 6. Initial burst release at $1 \mathrm{~h}$ was $27.26 \pm 2.52$ and $10.17 \pm 0.39 \%$ respectively for F1 and F4. The MDT value (Table 2) for F1 (at 100 $\mathrm{rpm})$ was $3.16 \mathrm{~h}$ and in the case of F4 it was $4.87 \mathrm{~h}$. The tablets in case of $\mathrm{F} 1$ were completely eroded by the end of $10 \mathrm{~h}$, whereas in case of F4, the integrity of the tablets was maintained throughout $12 \mathrm{~h}$. Hence, keeping in view of drug release profiles obtained with F1 and F4, F4 with $20 \% \mathrm{w} / \mathrm{w}$ HPMC K4M was selected as core formulation.

Since CPT is poorly water soluble drug, its release from CR matrix tablet is incomplete and therapeutically effective drug levels may not be achieved. Hence, in the present investigation cyclodextrins like $\beta-C D$ and HP- $\beta-C D$ at a level of $20 \% \mathrm{w} / \mathrm{w}$ of total tablet weight (F5 and F6) were included in the formulations and their effect on the CPT release was studied in order to achieve therapeutically effective levels of CPT. A $96.23 \pm 1.27 \%$ CPT release was observed at end of $12 \mathrm{~h}$ with F5 containing $\beta-\mathrm{CD}(20 \% \mathrm{w} / \mathrm{w})$ and $98.4 \pm 1.02 \%$ of $\mathrm{CPT}$ release was observed at end of $12 \mathrm{~h}$ with $\mathrm{F} 6$ containing HP- $\beta-C D(20 \% \mathrm{w} / \mathrm{w})$. The initial release of CPT at $1 \mathrm{~h}$ was $10.17 \pm 0.39,15.98 \pm 0.42$ and $22.27 \pm 0.92$ respectively for F4, F5 and F6. The addition of cyclodextrins significantly increased the initial burst release of CPT from the formulations. The CPT release was more with HP- $\beta$-CD when compared to $\beta$-CD. This is because of more hydrophilic nature of HP- $\beta-C D$ than the $\beta-C D$. 
Comparative in vitro dissolution profiles of F4, F5 and F6 were shown in Figure 4C.

Among all the formulations, F6 containing 20\% w/w HP- $\beta$-CD gave superior and required CPT release of $98.4 \pm 1.02 \%$ at the end of $12 \mathrm{~h}$ and fulfilled the regulatory requirements in terms of percent drug release.

H2* Release Kinetics and Mechanisms

Formulations F1 (100 rpm), F4, F5 and F6 were evaluated for release kinetics and mechanisms. The $\mathrm{R}^{2}$ values for F1 (100 rpm) obtained with First order plots were found to be superior when compared to $\mathrm{R}^{2}$ values of Zero order plots. These results indicated that the CPT release from F1 (100 rpm) followed First order kinetics (Table 3). In case of F4, F5 and F6, $\mathrm{R}^{2}$ values obtained from Zero order plots were found to be superior when compared to $\mathrm{R}^{2}$ values obtained from First order plots indicating that $\mathrm{CPT}$ release from F4, F5 and F6 followed Zero order kinetics.

The Higuchi square root model showed higher correlation coefficient values (0.949-0.990) indicating diffusion was the release mechanism for CPT from F1 (100rpm), F4, F5 and F6. The graphs of $\log \%$ QT versus $\log$ $\mathrm{t}$ showed a linear relationship with $\mathrm{R}^{2}$ values ranging from $0.992-1.0$ and ' $n$ ' values obtained by fitting initial $60 \%$ cumulative CPT release data from F1 $(100 \mathrm{rpm})$, F4, F5 and F6 in to Korsmeyer Peppas equation ranged between 0.548-0.874 indicating anomalous transport (both diffusion and erosion) as CPT release mechanism from CPT CR matrix tablets (Table 3).

\section{CONCLUSION}

CPT, a poorly water soluble drug can be formulated in to $\mathrm{CR}$ matrix tablets using HPMC K4M as release retardant and MCC as filler for better therapeutic efficacy in order to make this molecule to a successful anticancer drug. Addition of solubilising agents like HP- $\beta-C D$ significantly increased the dissolution of CPT within tablet core and enhanced the release rate.

\section{ACKNOWLEDGEMENTS}

The authors are thankful to Dr. U Das, Undurti Life Sciences, USA for providing gift sample of Camptothecin and to the Siddhartha Academy of General and Technical education, Vijayawada for providing facilities to carry out the research work.

\section{Highlights of Paper}

- Camptothecin (CPT) is a poorly water-soluble anti-cancer drug can be used for the treatment of colorectal, breast, lung and ovarian cancers.

- It has short half life and so, controlled release (CR) formulations are required for better therapeutic efficacy.

- Cyclodextrins were added in the CR tablet formulations to enhance the CPT solubility in order to ensure complete release of CPT from matrix tablets.

- Formulations containing $20 \% \mathrm{w} / \mathrm{w}$ of hydroxypropyl- $\beta$-cyclodextrin with microcrystalline cellulose as filler and HPMC K4M as release retardant gave superior CPT release (F6) and fulfilled the regulatory requirements.

\section{Author Profile}

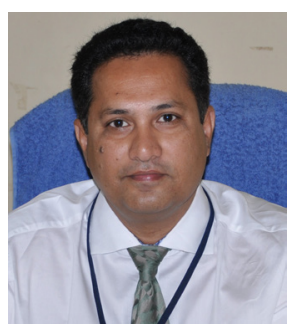

- Prior to joining in KVSRCOPS, Dr. Nalluri worked as Postdoctoral fellow/Research Associate at University of Kentucky, USA and as Principal Scientist at Yaupon Therapeutics Inc. Dr. Nalluri obtained Ph.D. in pharmaceutical sciences from the College of Pharmaceutical Sciences, Andhra University (2002) and has won many awards throughout his academic career including UGC Research Fellowship (1997), best research paper award in pharmaceutics by IDMA, Mumbai (2000) and best PhD thesis in pharmaceutical sciences award (JJ Rao Gold Medal) by Andhra University (2003). He is PI of 3 research grants (funded by AICTE and DST) and published and presented 50 research papers. 


\section{REFERENCES}

1. Wall ME, Wani MC. Camptothecin and Taxol: from discovery to clinic. Journal of Ethnopharmacol 1996; 51(1-3): 239-53.

2. Biswajit Basu, Kevin Garala, Ravi Bhalodia, Bhavik Joshi, Kuldeep Mehta. Solid lipid nanoparticles: A promising tool for drug delivery system. Journal of Pharmacy Research 2010; 3(1): 84-92.

3. Kang J, Kumar V, Yang D, Chowdhury PR, Hohl RJ. Cyclodextrin complexation: Influence on the solubility, stability, cytotoxicity of Camptothecin, an antineoplastic agent. European Journal of Pharmceutical Sciences 2002; 15(2): 163-70.

4. Naveen K, Thakral AR, Daniel BS, Andre HE, Dipak KM. Soluplus-solubilized citrated Camptothecin-A potential drug delivery strategy in colon cancer. AAPS Pharm Sci Tech. 2012; 13(1): 59-66.

5. Shankar Swaminathan, Linda Pastero, Loredana Serpe, Francesco Trotta, Pradeep Vavia, et al. Cyclodextrin-based nanosponges encapsulating camptothecin: physicochemical characterization, stability and cytotoxicity. European Journal of Pharmaceutics and Biopharmaceutics 2009; 74(2): 193-201.

6. Cortesi R, Esposito E, Maietti A, Menegatti E, Nastruzzi C. Formulation study for the antitumor drug Camptothecin: liposomes, micellar solutions and a microemulsion. International Journal of Pharmaceutics 1997; 159(1): 95-103.

7. Daoud SS, Fetouh MI, Giovanella BC. Antitumor effect of liposomesincorporated Camptothecin in human malignant xenografts. Anti-cancer drugs 1995; 6(1): 83-93.

8. Ann Mari S, Goril EF, Martin B. A method to determine the incorporation capacity of Camptothecin in liposomes. AAPS Pharm Sci Tech. 2004; 5(3): 30-7.

9. Ryotaro Kunii, Hiraku Onishi, Yoshiharu Machida. Preparation and antitumor characteristics of PLA/PEG-PPG-PEG) nanoparticles loaded with Camptothecin. European Journal of Pharmaceutics and Biopharmaceutics 2007; 67(1): 9-17.

10. Shankar S, Linda P, Loredana S, Francesco T, Pradeep V, Dino A, et al. Cyclodextrin-based nanosponges encapsulating Camptothecin:
Physicochemical characterization, stability and cytotoxicity. European Journal of Pharmaceutics and Biopharmaceutics 2010; 74(2): 193-201.

11. Lei Yang, Fude Cui, Dongmei Cun, Anjin Tao, Kai Shi, Wenhui Lin. Preparation, characterization and bio distribution of the lactone form of 10-hydroxycamptothecin (HCPT)- loaded bovine serum albumin (BSA) nanoparticles. International of Journal of Pharmaceutics 2007; 340(1): 163-72.

12. Lev Bromberg T, Alan Hatton, Rafael Barreiro-Iglesias, Carmen Alvarez, Angel Concheiro. Controlled release Camptothecin tablets based on pluronic and poly (acrylic acid) copolymer. Effect of fabrication technique on drug stability, tablet structure and release mode. Drug Development and Industrial Pharmacy 2007; 33(6): 607-15.

13. Chen H, Jiang G, Ding F. Monolithic osmotic tablet containing solid dispersion of 10-hydroxycamptothecin. Drug Development and Industrial Pharmacy 2009; 35(2): 131-7.

14. The United State Pharmacopoeia. USP30-NF-25, Asian edition. M Rockville, United States Pharmacopoeial Convention Inc; 2007; 643-5.

15. Lachman L, Herbert AL, Joseph LK. The Theory and Practice of Industrial pharmacy. $3^{\text {rd }}$ Edition. Varghese publishing house; 1987; 296-300.

16. Brazel CS, Peppas NA. Modeling of drug release from swellable polymers. European Journal of Pharmaceutics and Biopharmaceutics 2000; 49(1): 47-58.

17. Lapidus H, Lordi NG. Drug release from compressed hydrophilic matrices. Journal of Pharmaceutical Sciences 1966; 55(8): 840-3.

18. Higuchi T. Mechanism of sustained action medication, theoretical analysis of rate of release solid drugs dispersed in solid matrices. Journal of Pharmaceutical Sciences 1963; 52(12): 1145-8.

19. Korsmeyer RW, Gurny R, Doelker E, Buri P, Peppas NA. Mechanism of solute release from porous hydrophilic polymers. International Journal of Pharmaceutical Sciences 1983; 15(1): 25-35.

20. The Merck Index. edited $12^{\text {th }}$ edition, Merck Research Laboratories, New Jersey, USA; 1996. 282. 